\title{
Paranoid styles and innumeracy: implications of a conspiracy mindset on Europeans' misperceptions about immigrants
}

\author{
Sergio Martini ${ }^{\star}$ (D), Mattia Guidi (D), Francesco Olmastroni (D), Linda Basile, Rossella Borri \\ and Pierangelo Isernia \\ Department of Social Political and Cognitive Sciences, University of Siena, Siena, Italy \\ *Corresponding author. Email: sergio.martini@unisi.it
}

(Received 29 July 2020; revised 9 June 2021; accepted 10 June 2021; first published online 27 July 2021)

\begin{abstract}
Innumeracy, that is, the inability to deal with numbers and provide correct estimates about political issues, is reported to be widespread among the public. Yet, despite the recognition that a conspiracy mindset is an increasingly common phenomenon in Western democracies, this has not been considered as a potential correlate of innumeracy. Using data from an online sample of respondents across 10 European countries, we show that those with a higher propensity to hold a conspiracy worldview tend to overestimate the actual share of the immigrant population living in their own country. This association holds true when accounting for country heterogeneity and other cognitive, affective and socio-demographic factors. Employing a comparative design and refined measurements, the article contributes to our understanding of how a conspiracy mentality may influence perceptions of relevant political facts, questioning basic processes of democratic accountability.
\end{abstract}

Keywords: Conspiracy mindset; conspiracy theories; Europe; immigration; innumeracy; misperception; refugee crisis

\section{Introduction}

Ordinary citizens may find it difficult to deal comfortably with numbers and statistics and are seldom capable of providing accurate estimates about politically relevant facts (Paulos, 1988; Gigerenzer and Edwards, 2003; Peters, 2006). Indeed, innumeracy applies to a wide range of issues, from estimating the size of national minority groups to gauging the share of the public budget devoted to different policies. This poses a serious threat to the basic mechanism of democratic accountability, since citizens take stances on political issues in line with figures they have in mind and decide to confirm or vote out incumbents based on the latter's perceived performance in these respects (Delli Carpini and Keeter, 1996; Kuklinski et al., 1998; Flynn et al., 2017).

Research has tried to explain differences in citizens' accuracy pointing at directionally motivated reasoning (Flynn et al., 2017). In this view, people would seek out information and form their opinions according to prior policy preferences and attitudes, pursuing belief consistency rather than accurate judgements. This is to say that people would evaluate the economy or the size of a given minority group according to their pre-existing ideological views or level of concern (Bartels, 2002; Herda, 2010, 2013). Other studies, however, have explained biased estimates by referring to cognitive processes. Following this logic, people would rather infer numbers and make estimates by relying on their background knowledge and personal experience to overcome the scarcity of information. As an example, people would use their personal financial situation as

(c) Società Italiana di Scienza Politica 2021. This is an Open Access article, distributed under the terms of the Creative Commons Attribution licence (http://creativecommons.org/licenses/by/4.0/), which permits unrestricted re-use, distribution, and reproduction in any medium, provided the original work is properly cited. 
a benchmark to rate their country's economic performance (Duch et al., 2000), or they would estimate the percentage of foreign-born population living in the country depending on their neighbourhood contacts with immigrants or exposure to the mass media (Nadeau et al., 1993; Herda, 2010, 2013).

This article contributes to the literature on innumeracy by evaluating the potential link with an increasingly relevant but so far neglected factor, namely holding a conspiracy mindset or a paranoid style of thinking. Conspiracy thinkers are said to show a monological belief system, such that when they find an explanation of a certain event, they do not search for external data or factual evidence but rather resort to more general explanations, so ignoring detailed examinations of the context and appealing to secret plots perpetrated by a conspiring group of (powerful) people (McClosky and Chong, 1985; Moscovici, 1987; Goertzel, 1994; Douglas et al., 2019). The same scheme is automatically retrieved when facing new and upcoming events, with judgements achieved by intuitive rather than analytic thinking (Swami et al., 2014). A conspiracy mindset is often associated with cognitive closure and the rejection of scientific knowledge (Leman and Cinnirella, 2013; Lewandowsky et al., 2013). Then, conspiracism seems to have an emotional basis, being correlated with anxiety (Grzesiak-Feldman, 2013) and the perception that society is under threat (Jolley et al., 2018). It is, thus, reasonable to expect a conspiracy mindset to lead people to hold unsupported beliefs about factual issues and provide incorrect estimates when facing controversial and large-scale events.

We test this expectation using survey data from an online sample of respondents collected across 10 European countries in 2017. We show that people with a higher propensity to hold a conspiracy mindset tend to overestimate the actual share of the immigrant population living in their own country. The association of innumeracy with the conspiracy thinking scale we employ holds true when accounting for country heterogeneity and other cognitive, affective and socio-demographic factors. Innumeracy about immigrants coming from outside the European Union (EU) is an interesting case that has lately attracted increasing attention of empirical research (Semyonov et al., 2004; Citrin and Sides, 2008; Herda, 2010, 2013; Isernia and Olmastroni, 2014; Duffy, 2018). The inflows of migrants from North Africa and the Middle East, culminated in the migration crisis of 2015, have reinforced an already widespread sense of insecurity (Börzel and Risse, 2018), with immigration and the refugee crisis being the object of prominent conspiracy theories that have spread in the public debate (Drochon, 2018).

Despite the limitations of any cross-sectional analysis in identifying causal paths, the article has some added values. First, it expands our understanding of the origins of innumeracy exploring how the spread of conspiracy thinking might affect opinion formation on relevant political facts, questioning an individual's capacity to make informed political choices. Second, it moves beyond traditional measures of belief in conspiracy theories, employing a scale aiming at revealing a more generalized tendency towards a conspiracy mindset. Third, it adds comparative evidence to the literature on the potential implications of conspiracy thinking, a field in which case-study research still constitutes the vast majority.

\section{Theoretical background}

\section{Defining and explaining innumeracy}

The notion of innumeracy refers to the inability to deal with notions such as risk and probability, also encompassing the tendency to under or overestimate facts and figures related to politically relevant issues (Paulos, 1988; Gigerenzer and Edwards, 2003; Peters, 2006; Flynn et al., 2017; Duffy, 2018). It has been found that people tend to misperceive the percentage of money spent on foreign aid (Scotto et al., 2017) and the state of macro-economy (Duch et al., 2000). Citizens also fail to provide accurate estimates of both the size of minorities in society, such as migrants (Herda, 2010; Duffy, 2018), ethnic groups (Nadeau et al., 1993; Alba et al., 2005; Citrin and Sides, 2008) and homosexuals (Martinez et al., 2008). Previous research indicates 
that innumeracy is a quite common characteristic in Western democracies, though variation has been observed across subgroups and national contexts in Europe and the United States.

One approach that has often been proposed to explain this variation builds on motivated reasoning (Flynn et al., 2017), arguing that people are moved in their opinions at least by two types of motivations (Kunda, 1990). On the one hand, those driven by accuracy goals would put cognitive effort to evaluate contradictory evidence related to a certain issue in order to come to correct conclusions. This type of motivated reasoner would approximate the ideal of the enlightened citizen eager to reach objective evaluations. Others, on the other hand, follow directional goals so that they aim at achieving conclusions that are aligned with prior attitudes. This would shape how people select and process information helping them build the best possible case to maintain consistency in their belief system.

One common variant of the latter view, at least in political psychology, considers the role of partisan identities and ideological preferences when forming opinions (Lodge and Taber, 2013). Accordingly, people might have a better (or worse) evaluation of the actual state of the economy or budget allocation depending on their party identification and electoral winner-loser status (Evans and Andersen, 2006; Scotto et al., 2017; Quaranta et al., 2020). This implies that evaluation of performance issues is often conditional to a process of partisan and ideological rationalization rather than the result of a critical assessment of available information. Similarly, when the size of the immigrant population within a local or national community is evaluated, nativeborn citizens' estimates will depend on whether they feel threatened or support anti-immigrant policies and positions. In this case, they will tend to overestimate the percentage of foreign-born individuals living in their country, whereas they will underestimate it if otherwise (Herda, 2010, 2013).

It has to be noted that estimates of people who are moved by accuracy goals are not necessarily free from bias, due to the heuristics underlying their reasoning strategies (Kunda, 1990). Individuals, in fact, may resort to cognitive shortcuts to overcome the scarcity of information when taking decisions, also extending ready-to-use evidence from their personal experience to infer figures and numbers. This cognitive process, also known as 'availability heuristic', has been documented to lead to potentially biased conclusions (e.g., Tversky and Kahneman 1973; Taylor 1982). Natives, therefore, might provide estimates of immigrants that are either larger or smaller than actual numbers due to their interpersonal contacts in a more or less ethnically diverse neighbourhood. It goes without saying that mass media exposure might act as a substitute for individuals who have occasional contacts or limited information, bringing those who are exposed more frequently to news regarding minority groups to revise their assessments of immigration-related issues (Herda, 2010, 2013).

All in all, innumeracy may have a motivational and a cognitive basis. Yet, an additional factor might come into play when forming evaluations of political issues: the individual tendency to misperceive reality, as it happens for conspiracy thinkers.

\section{Conspiracy thinking and (biased) opinion formation}

Belief in conspiracy theories derives from an underneath conspiracy ideation, a monological belief system resulting in a connection of interrelated and self-reinforcing cognitions that shape a worldview (Moscovici, 1987; Goertzel, 1994; Sutton and Douglas, 2014; Bost 2018). This worldview subsumes a general orientation towards a deterministic interpretation of public events as the result of the will of unseen and hidden forces; a view that is able to reduce complexity in an underlying binary Manichean narrative, immune to the rule of evidence (Oliver and Wood, 2014). There is a series of reasoning biases that characterize those holding a conspiracy mindset and that have been highlighted by previous research.

First, conspiracy thinkers favour explanations which are commensurate with the implications of an event, so that the larger and more complex the consequences are, the stronger the belief 
about the existence of some major cause is (Leman and Cinnirella, 2007). Second, it has been noted that conspiracy thinking is also connected to cognitive closure, that is, a tendency to misinterpret or ignore upcoming evidence in order to reduce ambiguity and favour already definite explanations (Leman and Cinnirella, 2013). In other words, conspiracy thinkers are likely to behave as directionally motivated reasoners evaluating information and events in the light of their pre-existing views (Douglas et al., 2019). Third, this rejection of analytical information is paired with the likelihood to dismiss scientific knowledge or consider traditional sources of data as not credible (Lewandowsky et al., 2013). Finally, a conspiracy mindset has been found to correlate with intuitive thinking - automatic and characterized by affective reactions - rather than analytic reasoning - neutral and based on close examination (Swami et al., 2014). This is also supported by research considering conspiracism as an emotional bias connected to anxiety and the perception that society is threatened (Jolley et al., 2018), a link that has been shown to be particularly relevant when evaluating ethnic and national groups (Grzesiak-Feldman, 2013).

Most empirical research has focused on the factors explaining why a certain number of people believe in conspiracy theories. This considerably wide set of studies have explored the importance of personality traits (Douglas et al., 2019), demonstrating that a conspiracy mentality is negatively related to an individual's level of agreeableness (exemplified by suspicion and antagonism) and positively related with her or his openness to experience (measured as the propensity to embrace new ideas) (Swami et al., 2010). Other research has focused on the role of additional psychological variables, highlighting an association with political cynicism, a more pronounced authoritarian personality, feeling of powerlessness and lower self-esteem (Abalakina-Paap et al., 1999). Last, several studies have analysed the importance of political proclivities, showing that conspiracy believers are more represented in specific political or ideological groups (Mancosu et al., 2017; van Proojien, 2017).

One drawback of this research, however, has to do with survey measurement. Researchers often ask respondents if they believe in specific conspiracy theories about a wide array of events (e.g., the appearance of new diseases, the assassination of political leaders or the alleged adverse effects of vaccination) that are often context-dependent. This raises issues of validity across countries and over time (Enders and Smallpage, 2018). While scholars have developed more abstract scales in the attempt to gauge a more generalized tendency towards a conspiracy mindset or a paranoid style of thinking (McClosky and Chong, 1985; Brotherton et al., 2013; Bruder et al., 2013; Imhoff and Bruder, 2014), more substantial research needs to be pursued using these new survey instruments in different contexts. Indeed, another related shortcoming in the available literature is the lack of comparative evidence. Up to date, most studies are based on single case-studies (Douglas et al., 2019), making any generalization of the observed relationships problematic.

Last, while it is quite evident that beliefs in conspiracy theories have social and political outcomes, research has mainly focused on their determinants, with remarkably less attention on their implications. Only a few studies have addressed the political consequences of conspiracy mentality, examining its effects on populist attitudes (Castanho-Silva et al., 2017; Erisen et al., 2021), political engagement (Jolley and Douglas, 2014) and voting behaviour (Mancosu et al., 2021). More investigation is therefore needed to understand whether and to what extent a conspiracy mindset may influence citizens' perceptions of events and the process of opinion formation at the basis of individuals' political choices.

\section{Conspiracy thinking and innumeracy about immigrants}

We argue that a conspiracy mindset, defined as the tendency to explain unfavourable events as the result of a secret plot by a conspiring group of powerful elites (Imhoff and Bruder, 2014), may explain people's bias in estimating important social and political events, thus undermining their capacity to make sense of the political realm through numbers and quantitative knowledge. Given the above arguments, we expect a conspiracy mindset to be associated with unsupported 
beliefs about factual issues and the tendency to provide incorrect estimates when faced with controversial and large-scale events. The case we consider concerns immigrant population innumeracy and it is relevant for several reasons.

To begin with, a recent Eurobarometer survey finds that, in many European countries, citizens offer estimates that are far off the real share when asked about the percentage of non-EU migrants hosted in their own country: in 2017, in 19 out of the 28 Member States, the estimated proportion in the population was at least twice the actual shares (European Commission, 2018). Similarly, empirical research exploring the breadth of innumeracy about immigration in Europe has shown a more frequent tendency to overestimate than to underestimate foreign-born population by native groups (Citrin and Sides, 2008; Herda, 2010, 2013; Isernia and Olmastroni, 2014; Duffy, 2018). Coming to the explanatory factors, previous studies have focused on the role of preexisting policy preferences or attitudes towards immigrants, hinging on motivated reasoning. In this respect, support for anti-immigrant policy, negative attitudes towards immigration and a higher perceived threat to the national community seem to be positively related to overestimation, while underestimation is more related to opposition to anti-immigrant policies and a lower perceived threat (Nadeau et al., 1993; Herda, 2010, 2013). ${ }^{1}$ Counterintuitively, a more conservative ideology seems to be associated with lower levels of immigration innumeracy (Herda, 2010).

Turning to cognitive factors, evidence is mixed. Research has found that neighbourhood contacts with foreign-born people are positively related to overestimation, but this indicator would be less efficient when discriminating those who overestimate from those who give correct estimates (Herda, 2010, 2013). As far as the role of the media is concerned, Blinder and Jeannet (2017) found immigrant population estimates to be sensitive to media contents and the way issues are framed. Similarly, Herda (2010) noted that media exposure affects innumeracy about immigrants, with some media being more relevant than others. While watching television is associated with greater innumeracy, the time spent reading newspapers seems to reduce the bias, although these results were partially disconfirmed in a later study in which the role of newspapers was downsized (Herda, 2013).

The issue of immigration has become increasingly relevant in the last few years as a consequence of the recent refugee crisis. Beyond contributing to the development of an increasing sense of insecurity and cultural threat among the European public, the inflows of immigrants and asylum seekers from North Africa and the Middle East have unrevealed the inability of the EU to find coordination and a fair sharing of the costs of the crisis among all its members (Bauböck, 2018; Börzel and Risse, 2018). According to Eurobarometer data, the relevance of this issue has grown substantially among the EU public, with $39 \%$ of respondents mentioning immigration as the most important problem faced by the EU in autumn 2017 (European Commission, 2020). While the inflow of migrants has contributed to rising scepticism and dissatisfaction towards the EU (Quaranta and Martini, 2019), it has been demonstrated that an overestimation of the immigrant population living in the country is negatively related to levels of support for intra-EU solidarity measures (Basile and Olmastroni, 2020).

Beyond the above-mentioned factors, the spread of conspiracy theories towards immigrants may have played an additional role in the misperceptions regarding the size of the crisis. Indeed, the migration issue has been the object of several conspiracy theories. One of the most popular claims is that a 'Great replacement' is taking place following a hidden plan by international elites aiming at destroying the Western civilization through the gradual substitution of the European citizenship with a non-white, Muslim population from non-European countries. This theory has reached the attention of the media also due to several prominent right-wing

\footnotetext{
${ }^{1}$ Building on Pettigrew et al. (1958), innumeracy has often been assumed to result from perceived threat. For qualitative research see Gallagher (2003), while for an opposite argument, see Semyonov et al. (2004).
} 
politicians such as Matteo Salvini in Italy ${ }^{2}$ and Viktor Orbàn in Hungary (Walker, 2019), who have contributed in propagating the message more or less explicitly. ${ }^{3}$

Amid this scenario, in 2016 more than $40 \%$ of Britons and Germans agreed with the fact that the government was deliberately hiding the truth about how many immigrants really lived in their country. Numbers were also high in other national contexts like Sweden (31\%) and Italy (29\%) (Drochon, 2018). More importantly, the share of citizens believing in such a plan persisted over the years (YouGov, 2018). ${ }^{4}$ Last, belief in conspiracy theories about certain minority groups has been found to be associated with increasing xenophobic attitudes and prejudice towards their members (Jolley et al., 2020). In brief, taking into account the salience of the migration issue at the time in which the survey used in the analysis was conducted (2017), the popularity of the conspiracy narrative in this regard and the tendency of adherents to a conspiracy worldview to reasoning bias, we expect that:

Hypothesis: The higher the degree of conspiracy thinking, the more a subject will overestimate the actual size of immigrants or asylum seekers in her/his country.

\section{Data and method}

To test our hypothesis, we use data from the second wave of the EUENGAGE online panel survey, ${ }^{5}$ conducted between 6 July and 6 October 2017. The sample includes 11,639 individuals before list-wise deletion of missing values for the variables of interest - aged 18 or older, living in one of the 10 surveyed EU member states (Czechia, France, Germany, Greece, Italy, the Netherlands, Poland, Portugal, Spain and the United Kingdom). Respondents were approached through an opt-in online panel provided by Research Now, using a non-probability quota sampling to reflect the country's adult population with access to the Internet on gender, age-group and region (Eurostat's NUTS2 classification). With the exception of educational attainment, the sample's distribution compares quite closely with the general population (see Online Appendix A). To improve the quality of the data (Baker et al., 2010), we remove those respondents who completed the interview in less than $50 \%$ of the median response time. This evaluation was carried out at country level, since response times are often dependent upon the language of the questionnaire. Below, we show analysis of unweighted data, while we include results applying post-stratification weights in the Appendix.

\section{Dependent variable}

In line with previous research (e.g., Herda 2010), we operationalize immigrant population innumeracy with a variable measuring the difference between people's estimated share (in percentage) of immigrants living in their country and the actual share resulting from official statistics. This measure offers a better estimate of citizens' innumeracy of a certain political fact, such as the

\footnotetext{
${ }^{2}$ See Sky TG24 web interview in 2016 available at: https://bit.ly/33Y17qv accessed on February 2021.

${ }^{3}$ The theory is often attributed to the French intellectual Renaud Camus, but it draws back to the writings of Austrian philosopher Richard von Coudenhove-Kalergi, who advocated for a confederation of European states in which ethnic cleavages would be overcome. Current right-wing conspiracy theories of a 'Great replacement' (see Bowles, 2019) draw on posthumous interpretations of Kalergi's writings, and gained visibility worldwide due to the terrorist attack perpetrated by a white supremacist against two mosques in Christchurch, New Zealand, in March 2019.

${ }^{4}$ In 2018, the percentage of respondents agreeing with the statement 'The Government is deliberately hiding the truth about how many immigrants really live in this country' was: France 32\%; Germany 35\%; Great Britain 30\%; Hungary 48\%; Italy 20\%; Poland 21\%; Portugal 13\%; Sweden 29\% (YouGov 2018).

${ }^{5}$ Respondents were recruited from the set of panellists who had completed the first wave of the EUENGAGE mass survey (14 June-20 July 2016).
} 
share of immigrant population in a national context, as compared to questions in which respondents are asked whether they approve or disapprove a given statement (i.e., whether immigration is rising or not), thus, avoiding a conformity bias (Flynn et al., 2017).

To build this variable, we use two versions of the same question asking respondents to estimate the percentage of immigrants living in their own country. One format refers to people born in non-EU countries, while the other refers to asylum seekers. Random assignment to one of the two question formats was implemented via a split-ballot design, allowing us to provide a more robust test of innumeracy and control for a potential group effect concerning different categorizations of migrants (De Coninck, 2020). ${ }^{6}$

Then, we compare these estimates with official figures on immigrants and asylum-seekers provided by Eurostat (2020) and UNHCR (2020). For quantifying immigrant population, we consider the ratio between the sum of residents that, as of 2016, were (a) from non-EU28 countries nor from reporting country; (b) stateless; (c) of unknown origin, and the total population. For asylum seekers, we calculate the share of asylum seekers in each country in 2016 out of the total population (see Online Appendix B). So, for each respondent, we calculate the dependent variable innumeracy ${ }^{i m m}$ or innumeracy $^{a s}$ (the proxy of the error for the number of immigrants or the number of asylum seekers) as follows:

$$
\begin{aligned}
\text { innumeracy }_{i c}^{i m m} & =\text { estimate }_{i c}^{i m m}-\text { correct }_{c}^{i m m} \\
\text { innumeracy }_{i c}^{a s} & =\text { estimate }_{i c}^{a s}-\operatorname{correct}_{c}^{a s}
\end{aligned}
$$

where the variables labelled "estimate" represent the respondent $i$ 's estimate (expressed in percentage) about the number of immigrants or asylum seekers in her/his country $c$, and the variables labelled "correct" are the actual values. We opt for excluding respondents who gave overly wrong values, which could be attributed to mis-typing, misunderstanding of the question or intentionally wrong answers. Using Tukey's (1977) criterion for identifying extreme outliers, we exclude all the observations outside the range $\left[Q_{1}-3\left(Q_{3}-Q_{1}\right), Q_{3}+3\left(Q_{3}-Q_{1}\right)\right]$, where $Q_{1}$ and $Q_{3}$ are the values corresponding to the first and third quartiles of the distribution. This leads us to exclude only overestimated responses, namely those higher than $62.58 \%$ in innumeracy $^{i m m}$ (93 observations) and those higher than $36.99 \%$ in innumeracy ${ }^{a s}$ (375 observations) (see Online Appendix B for the distribution of the dependent variables).

Figure 1 illustrates the average difference, by country, between the respondents' estimates about the number of immigrants or asylum seekers and the actual values. As we can see, the error about immigrants tends to be larger than the one about asylum seekers. The average error by country ranges from a minimum of $5.47 \%$ (in Portugal about asylum seekers) to a maximum of $14.07 \%$ (in the Netherlands about immigrants). This difference might be explained by less media coverage and hostility experienced by refugees. News coverage about refugees is generally episodic, whereas information about migrants is much more extensive. Moreover, migrants have long been framed as taking advantage of national welfare provisions, while refugees have been accounted for the dire situations forcing them to flee from their countries of origin. Indeed, previous research has shown that people tend to hold more positive attitudes towards this group than towards immigrants (De Coninck, 2020).

\footnotetext{
${ }^{6}$ The categories that people have in mind when asked about migrants may be numerous and favour either cognitive or affective innumeracy (Duffy 2018). We concentrate on two of the most relevant categories. The questions were presented as follows: 'To the best of your knowledge, what percentage of the total [NATIONALITY] population are immigrants? (By immigrants, we refer to people who were born in non-EU countries)' ( $N=5571)$; 'To the best of your knowledge, what percentage of the total [NATIONALITY] population are asylum seekers? (By asylum seeker, we refer to someone who has fled to another country, where s/he applied for asylum - i.e., the right to international protection from persecution)' $(N=5570)$. Respondents could insert an estimate using any number format, including decimals; no instruction on the format was provided to avoid priming effects.
} 


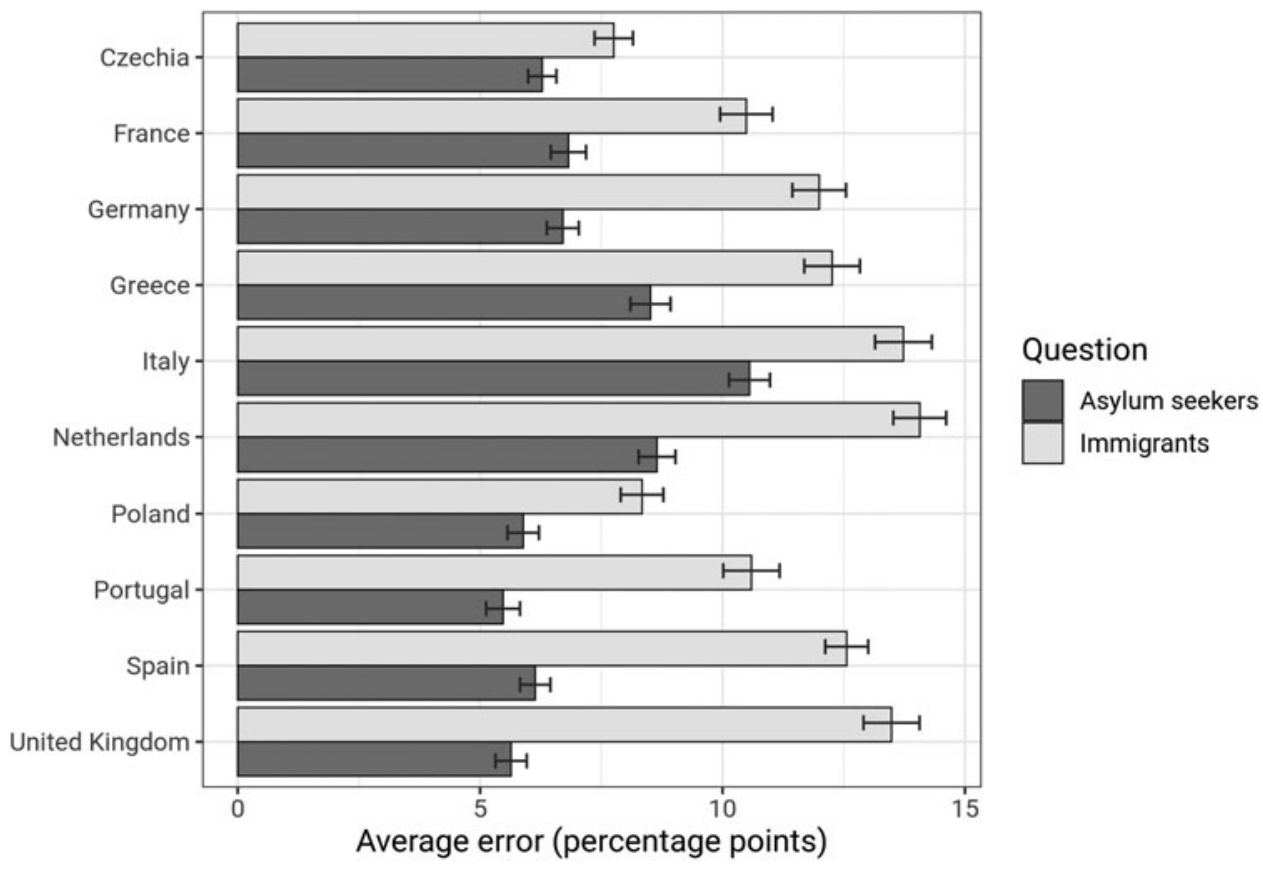

Figure 1. Average error in the estimation of immigrants and asylum seekers (extreme outliers excluded), by country. Error bars represent the $95 \%$ confidence interval.

Moreover, in line with available research (Herda, 2010, 2013; Duffy, 2018), most interviewees overestimate the percentage of migrants and asylum seekers. Only $12.7 \%$ of the respondents underestimate the number of non-EU immigrants, taking values lower than 0 on our measure, and only $2.9 \%$ underestimate the number of asylum seekers.

There is no agreement on the error threshold to be used in order to identify accuracy. If we use $-1 \%$ or $-2 \%$ thresholds to identify 'underestimators', numbers reduce substantially $(7.5 \%$ and $4.5 \%$ for immigrants, $0 \%$ for asylum seekers). For this reason, we decide to treat our outcome variable in its raw form to benefit from an interpretation based on percentage points and to avoid introducing any bias (Herda, 2010). ${ }^{7}$ Last, we test our hypothesis with a measure of innumeracy for both groups - immigrants and asylum seekers - and with an indicator combining the two variables.

\section{Explanatory variables}

Our main explanatory variable, conspiracy thinking, is a factor score derived from a confirmatory factor analysis (CFA) run on a four-item battery developed by McClosky and Chong's (1985) and assessing people's paranoid tendencies in politics or a general conspiracy thinking. This is elicited by asking respondents their level of agreement or disagreement with the following statements: (a) 'We would be much better off now if our foreign affairs were conducted out in the open, for all to see, rather than secretly'; (b) 'Most of the news we get from the press and the radio is deliberately slanted to mislead us'; (c) 'I often feel that the really important matters are decided behind the scenes, by people we never even hear about'; (d) 'The people think they govern themselves, but

\footnotetext{
${ }^{7}$ We do not have reasons to expect those with low conspiracy thinking to underestimate immigration. However, we have replicated the analysis excluding respondents who underestimated the percentage of either immigrants or asylum seekers and we did not find significant changes. Results are available on request.
} 
they really don't'. The answers were recorded on a four-point scale: 1 'Strongly agree'; 2 'Somewhat agree'; 3 'Somewhat disagree'; 4 'Strongly disagree'. We test the consistency of our measurement across countries with a multi-group CFA. The model that we choose for deriving the factor scores is a so-called 'configural model' - one in which loadings, intercepts and residual variances are allowed to vary in each country (details on measurement tests are reported in Online Appendix C). Overall, our analysis establishes that our items pertain to the same construct (Cronbach's $\alpha=0.725$ ). Consequently, we use the scores calculated from the model as a proxy of each respondent's level of 'conspiracy thinking'. To facilitate the interpretation of our findings, the score is re-scaled to make it range from 0 to 1 .

Along with our measure of a conspiracy mindset, we control for other relevant factors that have been found to affect people's propensity to misperceive political facts (Duffy, 2018; Flynn et al., 2017; Herda, 2010). Among cognitive factors, we gauge citizens' news consumption habits to ascertain whether their innumeracy levels are conditioned by the frequency they receive information from different media outlets during a normal week. This is measured on a nine-point scale ranging from 'never' to 'everyday'.

Moreover, we include the level of self-confidence held by a subject with respect to a specific task. Psychology research, in fact, shows that individuals have a general tendency to hold favourable views of their abilities and that this is even truer in less competent subjects. Thus, low competence is related not only to worse performance but also to inflated self-assessment of one's own capacity (Dunning, 2011). This expectation has been backed by empirical evidence related to the context of innumeracy, since there seems to be a strong relationship between incorrect perceptions and confidence at the aggregate level (Duffy, 2018). Yet, results seem to be less certain at the individual level, with other studies showing that confidence and accuracy on political issues would not be correlated (Lee and Matsuo, 2018). In the survey, after having asked respondents about their estimate of immigrants or asylum seekers over the whole country's population, a further question gauged their level of confidence about the fact that the answer they had just provided was correct. Using this indicator, we can distinguish respondents who were 'confident' about their estimates from those who were 'not confident' (reference category).

We expect innumeracy to be more pronounced among those who distrust official statistics (Holt, 2008). Trust is an essential element for cohesive societies as it makes cooperation viable, resulting in a series of positive societal outcomes, from economic prosperity and increased trade to quality of democracy. Trust may be conceived as a three-part relationship in which the truster trusts another agent (i.e., the trustee) with respect to a certain action. As a result, trust is also defined as the belief of the other party's trustworthiness based on the expectation that the latter would not betray us because of an alignment of interests (Hardin, 2002). Depending on the object of trust (i.e., another person, group or institution), this comes in different guises. Lack of trust in official statistics may undermine trust in branches of government that provide them, with the former being often conceived as a precondition for other forms of trust towards representative institutions (Holt, 2008). After all, it is possible that a conspiracy mindset would be associated with higher levels of innumeracy due to a substantial reduction in trust towards authoritative sources of information (Einstein and Glick, 2015). Hence, we take into account whether respondents did or did not (reference category) retain 'trust' in official statistics, as this might be a possible confounder in our analysis.

We also introduce controls for some affective and political factors that have been shown to influence individuals' orientations towards migrants. First, it might be expected that considering the flow of migrants to Europe as a concrete threat would foster perceptions of invasion from foreigners (Herda, 2010). Thus, we control for whether respondents were or not (reference category) 'concerned' about immigration.

Then, we control for the respondent's ideological self-placement. Immigration has proved to be a very polarizing issue along ideological lines, with right-wing parties (both mainstream and extreme) 'owning' it consistently in the eyes of the voters (Thränhardt, 1995; Bale 2003), albeit with 
contrasting evidence (Mudde, 1999; Alonso and Claro da Fonseca, 2012). So, in line with the literature, we expect right-wing voters to oppose immigration more than left-wing ones, leading the former to overestimate the threat posed by immigration, and, consequently, overestimate its size.

Finally, we control for gender, age, education, household income and area of residence (Semyonov et al., 2004; Herda, 2010). Education is perhaps the most relevant sociodemographic variable, being associated with political interest and knowledge (Delli Carpini and Keeter, 1996). As more educated people are more likely to evaluate correctly changes in social and political phenomena, showing lower degrees of innumeracy (Herda, 2010; Duffy, 2018), we control for education distinguishing respondents with 'high education' ('tertiary' education) from those with 'low education' ('primary' and 'secondary' education, reference category). Household income allows us to have a measure of economic vulnerability, which might increase the tendency to misperceive the size of immigration. The area of residence, instead, permits to control for the extent to which an individual is likely to come into contact with cultural differences, a factor that might influence immigration innumeracy as well. For comparability's sake, we rescale all the explanatory variables measured at the interval level into a $0-1$ range, with the exception of age. Table 1 displays descriptive statistics for all the variables. (Correlation among explanatory variables seem not to be a problem, see Online Appendix D. For question wording and more information on their operationalization, see Online Appendix E.)

\section{Empirical analysis}

We test our hypothesis with a linear regression model summarized by the following notation:

$$
\begin{gathered}
y_{i c}=\beta X_{i c}+z_{c}^{\prime} \alpha+\varepsilon_{i c} \\
\varepsilon_{i c} \sim N\left(0, \sigma_{\varepsilon}\right)
\end{gathered}
$$

where $y_{i c}$ is the innumeracy of respondent $i$ in country $c, X_{i c}$ is a matrix of explanatory variables with their respective coefficients $\beta, z_{c}^{\prime}$ is a vector of country fixed effects with their respective coefficients $\alpha$, which allow capturing country-level unobserved variation, and $\varepsilon_{i c}$ is the residual error term. ${ }^{8}$ To reduce the skewness of the dependent variables, we normalize them via Yeo-Johnson's transformation (Yeo and Johnson, 2000).

The results of the regression analysis are shown in Table 2, where we present three models: ${ }^{9}$ the first having as dependent variable the error in the estimation of non-EU immigrants; the second having as dependent variable the error in the estimation of asylum seekers; the third combining the two variables into a single one. As we can see, in all the considered models, the association between conspiracy thinking and immigration innumeracy is in line with our expectation and robust to the inclusion of different controls: a higher conspiracy mentality is associated to an overestimation of the number of both immigrants and asylum seekers, thus confirming our hypothesis.

As for cognitive factors, a higher level of exposure to political news on television is negatively associated with innumeracy both when the subjects to be estimated are non-EU immigrants and when the outcome variable combines estimates for immigrants and asylum seekers. These findings partially contradict previous research (Herda, 2010, 2013), but they fundamentally

\footnotetext{
${ }^{8}$ Our analysis cannot avoid the potential circularity of studying attitude-to-attitude relationships. Though we use a general measure of conspiracy mindset rather than beliefs in a specific conspiracy theory about immigration, the causal ordering of the variable is difficult to identify with certainty.

${ }^{9}$ To check for multicollinearity, we have calculated generalized variance inflation factors for all the variables included in the full model. All the values are very low, ranging from 1.01 to 1.56 . These models were also preceded by a series of tests in which variables were included stepwise and overall our results are stable and consistent.
} 
Table 1. Descriptive statistics of the variables used in the analysis

\begin{tabular}{|c|c|c|c|c|c|c|c|}
\hline Statistic & $N$ & Mean & St. Dev. & Min & $\operatorname{Pctl}(25)$ & $\operatorname{Pctl}(75)$ & Max \\
\hline Innumeracy abt. imm. & 5478 & 11.462 & 12.412 & -5.774 & 2.338 & 17.338 & 62.338 \\
\hline Innumeracy abt. as. seek. & 5195 & 7.093 & 8.178 & -0.371 & 0.992 & 9.928 & 36.928 \\
\hline Innumeracy (combined) & 10,673 & 9.335 & 10.788 & -5.774 & 1.338 & 14.513 & 62.338 \\
\hline Conspiracy thinking & 11,119 & 0.681 & 0.168 & 0 & 0.586 & 0.808 & 1 \\
\hline Self-confidence & 11,139 & 0.352 & 0.478 & 0 & 0 & 1 & 1 \\
\hline Trust in off. stat. & 11,139 & 0.432 & 0.495 & 0 & 0 & 1 & 1 \\
\hline High education & 11,122 & 0.539 & 0.499 & 0 & 0 & 1 & 1 \\
\hline Left-right self-placement & 11,136 & 0.503 & 0.187 & 0 & 0.4 & 0.6 & 1 \\
\hline Age & 11,141 & 48.526 & 14.780 & 18 & 37 & 61 & 91 \\
\hline Gender (female) & 11,141 & 0.491 & 0.500 & 0 & 0 & 1 & 1 \\
\hline Concern abt. imm. & 11,141 & 0.806 & 0.395 & 0 & 1 & 1 & 1 \\
\hline News on TV & 11,130 & 0.678 & 0.356 & 0 & 0.375 & 1 & 1 \\
\hline News on paper & 11,140 & 0.460 & 0.375 & 0 & 0.125 & 0.875 & 1 \\
\hline News on social media & 11,137 & 0.459 & 0.406 & 0 & 0 & 1 & 1 \\
\hline Income & 9567 & 0.345 & 0.225 & 0.091 & 0.182 & 0.455 & 1 \\
\hline Living in metropolitan zone & 11,140 & 0.337 & 0.473 & 0 & 0 & 1 & 1 \\
\hline Living in non-metr. zone & 11,140 & 0.413 & 0.492 & 0 & 0 & 1 & 1 \\
\hline Living in rural zone & 11,140 & 0.249 & 0.433 & 0 & 0 & 0 & 1 \\
\hline
\end{tabular}

substantiate its main conclusions. It is, in fact, hard to determine a priori whether media consumption would increase or decrease innumeracy. While the sign of the coefficients would suggest a more negative effect of exposure to TV than to newspapers and social media contents on providing inaccurate estimates, news exposure may also contribute to provide a distort representation of the size of the phenomenon. Much will probably depend on the accuracy of news in itself and the valence of framing.

Considering now the two factors pertaining to self-confidence and trust in official statistics, we observe that those who are confident about their estimates of immigrants are also more likely to exhibit a bias. While the same does not occur for asylum seekers - for which, we actually observe a weak negative relationship - the coefficient is positive and significant in the third model. These results add on existing mixed findings (Duffy, 2018; Lee and Matsuo, 2018). We have included trust in official statistics to control for a possible confounder. Interestingly, this has always a negative impact on innumeracy, meaning that people who express more trust in official statistics tend to be less wrong in their estimation.

Coming to the controls pertaining to the affective dimension, we can see that those who are more concerned about immigration tend to show an upward bias when estimating both immigrants and asylum seekers, and right-wing respondents tend to err more than left-wing ones. Our results for political ideology confirm that immigration is a polarizing issue along ideological lines (Thränhardt, 1995; Bale, 2003) and that voters closer to the right of the ideological spectrum are more likely to overestimate the share of immigrants living in their own country. Such results confirm previous research on the role of affective variables (Herda, 2010, 2013), but shed new light on the relevance of ideology. Last, among the socio-demographic controls, we provide support for the role of education as a suppressor of immigrant population innumeracy (Strabac, 2011). While the area of residence is not associated with the degree of innumeracy, income is negatively associated with innumeracy in the second and third models, suggesting a role for economic vulnerability with respect to immigration innumeracy (Semyonov et al., 2004). Last, in the third model, we use a dummy variable indicating whether the respondent was asked to estimate the number of non-EU immigrants or asylum seekers (reference category) as a control for the question wording received. The positive significant effect of the dummy tells us that innumeracy is larger among respondents who had to evaluate the number of non-EU immigrants. 
Table 2. Multiple linear regression models

\begin{tabular}{|c|c|c|c|}
\hline & \multicolumn{3}{|c|}{ Dependent variable: error in estimation of } \\
\hline & $\begin{array}{c}\text { Non-EU immigrants } \\
\text { (1) }\end{array}$ & $\begin{array}{c}\text { Asylum seekers } \\
\text { (2) }\end{array}$ & $\begin{array}{c}\text { (Combined) } \\
\text { (3) }\end{array}$ \\
\hline Conspiracy thinking & $\begin{array}{l}2.463^{\star \star \star} \\
(0.380)\end{array}$ & $\begin{array}{l}0.482^{\star \star \star} \\
(0.073)\end{array}$ & $\begin{array}{l}1.787^{\star \star \star} \\
(0.202)\end{array}$ \\
\hline Self-confidence & $\begin{array}{l}0.662^{\star \star \star} \\
(0.124)\end{array}$ & $\begin{array}{l}-0.081^{\star *} \\
(0.026)\end{array}$ & $\begin{array}{l}0.257^{\star \star \star} \\
(0.067)\end{array}$ \\
\hline Trust in official statistics & $\begin{array}{l}-0.853^{\star \star \star} \\
(0.124)\end{array}$ & $\begin{array}{c}-0.122^{\star \star \star} \\
(0.025)\end{array}$ & $\begin{array}{l}-0.531^{\star \star \star} \\
(0.066)\end{array}$ \\
\hline News on TV & $\begin{array}{r}-0.491^{\star} \\
(0.193)\end{array}$ & $\begin{array}{r}-0.079^{\star} \\
(0.037)\end{array}$ & $\begin{array}{c}-0.331^{\star \star} \\
(0.102)\end{array}$ \\
\hline News on paper & $\begin{array}{c}-0.253 \\
(0.178)\end{array}$ & $\begin{array}{c}-0.054 \\
(0.035)\end{array}$ & $\begin{array}{c}-0.157 \\
(0.094)\end{array}$ \\
\hline News on social media & $\begin{array}{c}0.051 \\
(0.162)\end{array}$ & $\begin{array}{c}0.014 \\
(0.030)\end{array}$ & $\begin{array}{r}-0.0001 \\
(0.083)\end{array}$ \\
\hline Concerned abt. Immigration & $\begin{array}{l}0.514^{\star * \star} \\
(0.156)\end{array}$ & $\begin{array}{l}0.193^{\star * *} \\
(0.028)\end{array}$ & $\begin{array}{l}0.494^{\star \star *} \\
(0.081)\end{array}$ \\
\hline High education & $\begin{array}{l}-0.752^{\star \star \star} \\
(0.131)\end{array}$ & $\begin{array}{l}-0.189^{\star \star \star} \\
(0.025)\end{array}$ & $\begin{array}{l}-0.605^{\star \star \star} \\
(0.069)\end{array}$ \\
\hline Left-right & $\begin{array}{l}2.036^{\star \star \star} \\
(0.312)\end{array}$ & $\begin{array}{l}0.447^{\star \star \star} \\
(0.058)\end{array}$ & $\begin{array}{l}1.542^{\star \star \star} \\
(0.163)\end{array}$ \\
\hline Age & $\begin{array}{l}-0.021^{\star \star \star} \\
(0.004)\end{array}$ & $\begin{array}{l}-0.004^{\star \star \star} \\
(0.001)\end{array}$ & $\begin{array}{l}-0.015^{\star \star \star} \\
(0.002)\end{array}$ \\
\hline Female & $\begin{array}{l}1.783^{* * *} \\
(0.124)\end{array}$ & $\begin{array}{l}0.318^{\star \star \star} \\
(0.024)\end{array}$ & $\begin{array}{l}1.230^{* * *} \\
(0.065)\end{array}$ \\
\hline Income & $\begin{array}{c}-0.538 \\
(0.332)\end{array}$ & $\begin{array}{l}-0.451^{\star \star \star} \\
(0.061)\end{array}$ & $\begin{array}{l}-0.854^{\star \star \star} \\
(0.174)\end{array}$ \\
\hline Living in metropolitan area & $\begin{array}{c}-0.012 \\
(0.159)\end{array}$ & $\begin{array}{c}-0.058 \\
(0.030)\end{array}$ & $\begin{array}{c}-0.046 \\
(0.084)\end{array}$ \\
\hline Living in rural area & $\begin{array}{c}-0.043 \\
(0.150)\end{array}$ & $\begin{array}{l}0.008 \\
(0.029)\end{array}$ & $\begin{array}{c}0.003 \\
(0.079)\end{array}$ \\
\hline Question abt. non-EU immigrants & & & $\begin{array}{l}0.751^{\star \star \star} \\
(0.060)\end{array}$ \\
\hline Constant & $\begin{array}{c}0.888 \\
(0.462)\end{array}$ & $\begin{array}{l}1.060^{\star \star \star} \\
(0.089)\end{array}$ & $\begin{array}{l}0.805^{\star * *} \\
(0.243)\end{array}$ \\
\hline Observations & 4670 & 4468 & 9138 \\
\hline $\begin{array}{l}R^{2} \\
\text { Adjusted } R^{2}\end{array}$ & $\begin{array}{l}0.150 \\
0.146\end{array}$ & $\begin{array}{l}0.186 \\
0.182\end{array}$ & $\begin{array}{l}0.152 \\
0.149\end{array}$ \\
\hline Residual Std. Error & 3.900 & 0.742 & 2.881 \\
\hline F statistic & $35.711^{\star \star \star}$ & $44.219^{\star \star \star}$ & $67.841^{\star \star \star}$ \\
\hline
\end{tabular}

Note: The dependent variable has been normalized with Yeo-Johnson's transformation. Standard errors calculated with the $\mathrm{HC}_{3}$ covariance matrix proposed by MacKinnon and White (1985), clustered by country. Country fixed effects included in all models.

Significance levels: ${ }^{\star} P<0.05 ;{ }^{\star \star} P<0.01 ;{ }^{\star \star \star} P<0.001$.

Since the dependent variables have been transformed, the interpretation of regression coefficients is not particularly informative. Therefore, it is convenient to visualize the effect of conspiracy mentality on innumeracy with the graphs in Figure 2. As for the estimation of immigrants, a respondent with the minimum score in conspiracy mentality will, on average, overestimate the actual figure by around 4.02 percentage points, while a person with the maximum score will overestimate it by around 10.31 percentage points. As regards the estimation of asylum seekers, the impact of conspiracy thinking is less pronounced: a respondent with the minimum score in conspiracy mentality will, on average, overestimate the real percentage by around $2.23 \%$, while a person with the maximum score will exceed it by around $4.66 \%$.

To conclude, we run a series of robustness checks. To test for model mis-specification, we run the Generalized Information Matrix test proposed by King and Roberts (2015): the results 

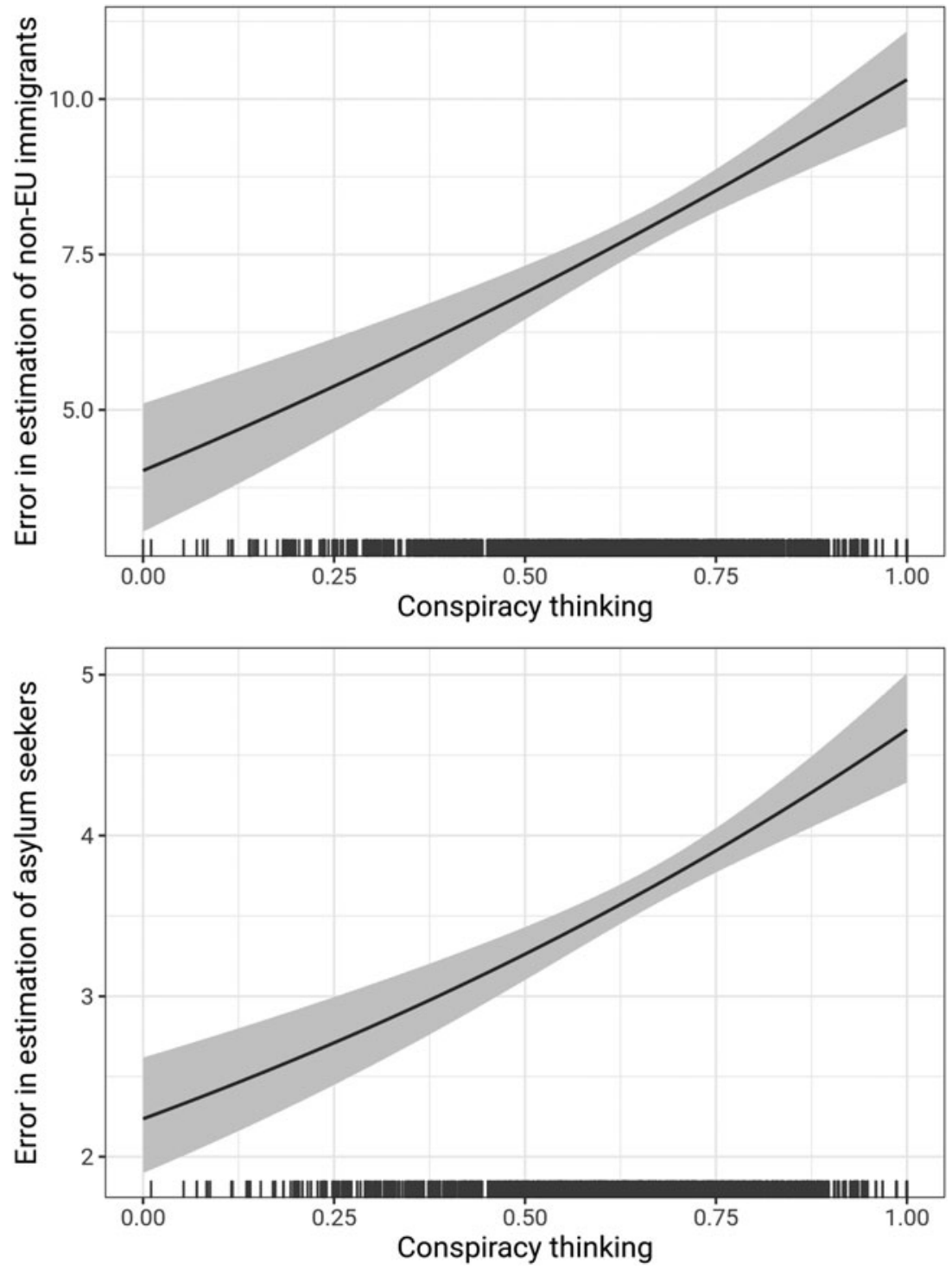

Figure 2. Estimated effect of conspiracy thinking on the error in estimating the number of immigrants or asylum seekers (simulation based on Models 1 and 2, Table 2). The small vertical lines at the bottom represent the probability distribution of the explanatory variable.

indicate no evidence of mis-specification. ${ }^{10}$ Since we have excluded extreme outliers from the responses in our dependent variables, we implement the same analysis with the full dataset: results do not seem to depend on the inclusion/exclusion of extreme outliers. We also replicate the analysis with weights to adjust our sample to the actual demographic composition of each country's adult population with access to the Internet, and, again, no substantial differences in results are found (see Online Appendix F).

\footnotetext{
${ }^{10}$ The test calculates the ratio between the 'classic' standard errors of the coefficients and the robust ones. Since the maximum ratio of robust-to-classic standard errors in all models is 1.18, we cannot reject the null hypotheses that models are correctly specified. The test has been performed using the package RobustSE in R (https://github.com/IQSS/RobustSE).
} 


\section{Conclusions}

The study of political ignorance has a prominent place in the analysis of public opinion, since the lack of knowledge about important political issues may produce detrimental effects on individuals' political behaviour (Delli Carpini and Keeter, 1996; Kuklinski et al., 1998; Flynn et al., 2017). More importantly, a biased perception of important social and political facts, such as innumeracy, may represent a threat to democratic accountability because of its impact on positional considerations from which we make political choices or take action.

When coming to possible explanations, this article has considered the role of a so-far overlooked factor, the tendency to hold a conspiracy mindset. Conspiracism is nothing new in human history; yet, in modern societies, this has constituted a system of thought and also a way to mobilize political action (Moscovici, 1987; McClosky and Chong, 1985; Goertzel, 1994). Our argument is that because people holding a conspiracy mindset exhibit peculiar cognitive and emotional features, they are more likely to provide biased estimates about social and political events. Research shows, in fact, that conspiracy thinkers are more prone to intuitive thinking and cognitive closure. They tend to reject evidence on social and political phenomena to corroborate pre-existing beliefs about secret plots hatched by powerful elites. Hence, conspiracy thinkers would refrain from collecting and processing external information and would rather rely on alternative and suspicious explanations to account for controversial and large-scale events.

We have applied this rationale to the study of innumeracy about immigration. The issue has attracted much attention in the last few years both among academics and pundits. While studies have highlighted that Europeans tend to overestimate the size of immigrants in their own countries, factors used to explain individual variation produce mixed results (Herda, 2010, 2013; Duffy, 2018). Moreover, immigration has become one of the most relevant political issues at the EU level, and, importantly, it has been the subject of various conspiracy theories. In the light of this, a conspiracy mindset might be an additional factor to be considered so that people scoring higher on conspiracy thinking are also more likely to overestimate the percentage of immigrants living in their country.

Using data from an online sample of respondents collected across $10 \mathrm{EU}$ countries in 2017, we have confirmed previous findings showing that immigrant population innumeracy is diffused and that a large share of citizens in all countries under examination tend to overestimate the size of immigrants. Results support our main hypothesis that people with a higher propensity to hold a conspiracy mindset tend to overestimate the actual share of the immigrant population living in the country. The association of innumeracy with the conspiracy thinking scale we employ is robust and it holds true when accounting for country heterogeneity and other cognitive, affective and socio-demographic factors.

Our analysis is, of course, not free from limitations. The causal ordering between the two variables of interest may in fact be uncertain and a cross-sectional analysis such as the one we propose is not able to account for possible (unobserved) omitted variables that might affect this relationship. Future research should consider the possibility to better explore the causal path via longitudinal analysis or even envisage experiments in order to address the implications of conspiracy thinking on opinion formation, and, specifically, innumeracy, also considering other issues beyond immigration.

Still, the article offers some interesting takeaways. First, it contributes to the existing literature on innumeracy bringing a new factor into the picture and proving brand new results (Herda, 2010, 2013; Duffy, 2018). The article suggests that innumeracy might be related to more profound attitudinal outlooks that influence the way people both select and process information. Second, this study speaks to the literature on conspiracism, focusing on an element so far underexplored, that is, the potential implications of conspiracy thinking (Douglas et al., 2019). We do it by addressing two aspects. The first one pertains to survey measurement. While the vast majority of studies in the field usually employ questions tapping beliefs on specific conspiracy theories 
that might be context-dependent, we use a scale that has elicited latent propensity to hold a conspiracy mindset in a broad set of European countries, one of the first examples in this direction, to the best of our knowledge. The second aspect has to do with the comparative nature of the study. Previous research on conspiracy thinking is mainly based on case studies. We, instead, provide comparative evidence on the potential role of a conspiracy mindset on the individual likelihood to provide biased estimates on immigration.

Supplementary material. The supplementary material for this article can be found at https://doi.org/10.1017/ipo.2021.26.

Funding. This research received financial support from the project 'Bridging the gap between public opinion and European leadership: Engaging a dialogue on the future path of Europe EUENGAGE' (H2020-EURO-2014-2015/ H2020-EURO-SOCIETY-2014, Grant no. 649281) funded by the European Union's Horizon 2020 research and innovation programme. For information see: www.euengage.eu. No conflict of interest.

Data. The replication dataset is available at http://thedata.harvard.edu/dvn/dv/ipsr-risp.

Acknowledgments. We thank the Editors and the two anonymous reviewers for their comments. Isernia, Basile and Olmastroni designed the study, had full access to all the data in the study and took responsibility for its integrity. Guidi, Martini and Olmastroni analysed the data and interpreted the results. Martini, Guidi, Borri, Isernia, Basile and Olmastroni drafted the manuscript. Martini, Guidi and Olmastroni critically revised the manuscript. Isernia obtained funding for the study.

\section{References}

Abalakina-Paap M, Stephan WG, Craig T and Gregory WL (1999) Beliefs in conspiracies. Political Psychology 20, 637-647.

Alba R, Rumbaut RG and Marotz K (2005) A distorted nation: perceptions of racial/ethnic group sizes and attitudes toward immigrants and other minorities. Social Forces 84, 901-919.

Alonso S and da Fonseca S C (2012) Immigration. Left and Right. Party Politics 18, 865-884.

Baker R, Blumberg SJ, Brick JM, Couper MP, Courtright M, Dennis JM, Dillman D, Frankel MR, Garland P, Groves RM, Kennedy C, Krosnick J and Lavrakas PJ (2010) Research synthesis: AAPOR report on online panels. Public Opinion Quarterly 74, 711-781.

Bale T (2003) Cinderella and her ugly sisters: the mainstream and extreme right in Europe's bipolarising party systems. West European Politics 26, 67-90.

Bartels LM (2002) Beyond the running tally: partisan bias in political perceptions. Political Behavior 24, 117-150.

Basile L and Olmastroni F (2020) Sharing the burden in a free riders' land: the EU migration and asylum policy in the views of public opinion and politicians. European Journal of Political Research 59, 669-691.

Bauböck R (2018) Europe's commitments and failures in the refugee crisis. European Political Science 17, 140-150.

Blinder S and Jeannet A-M (2017) The 'illegal' and the skilled: effects of media portrayals on perceptions of immigrants in Britain. Journal of Ethnic and Migration Studies 44, 1444-1462.

Börzel TA and Risse T (2018) From the Euro to the Schengen crisis: European integration theories. Politicization, and Identity Politics. Journal of European Public Policy 25, 83-108.

Bost PR (2018) The truth is around here somewhere: integrating the research on conspiracy beliefs. In Uscinski JE (ed.), Conspiracy Theories and the People Who Believe Them. Oxford: Oxford University Press, pp. 269-284.

Bowles N (2019) 'Replacement theory,' a racist, sexist doctrine, spreads in far-right circles. The New York Times, March 18. Available at https://nyti.ms/3anO3gy (Accessed 25 March 2020).

Brotherton R, French CC and Pickering AD (2013) Measuring belief in conspiracy theories: the generic conspiracist beliefs scale. Frontiers in Psychology 4, 279.

Bruder M, Haffke P, Neave N, Nouripanah N and Imhoff R (2013) Measuring individual differences in generic beliefs in conspiracy theories across cultures: conspiracy mentality questionnaire. Frontiers in Psychology 4, 225.

Castanho-Silva B, Vegetti F and Littvay L (2017) The elite is up to something: exploring the relation between populism and belief in conspiracy theories. Swiss Political Science Review 23, 423-443.

Citrin J and Sides J (2008) Immigration and the imagined community in Europe and the United States. Political Studies 56, 33-56.

De Coninck D (2020) Migrant categorizations and European public opinion: diverging attitudes towards immigrants and refugees. Journal of Ethnic and Migration Studies 46, 1667-1686.

Delli Carpini MX and Keeter S (1996) What Americans Know about Politics and Why It Matters. New Haven, CT: Yale University Press.

Douglas KM, Uscinski JE, Sutton RM, Cichocka A, Nefes T, Ang CS and Deravi F (2019) Understanding conspiracy theories. Political Psychology 40, 3-35. 
Drochon H (2018) Who believes in conspiracy theories in Great Britain and Europe? In Uscinski JE (ed.), Conspiracy Theories and the People Who Believe Them. Oxford: Oxford University Press, pp. 337-346.

Duch HM, Palmer HD and Anderson CJ (2000) Heterogeneity in perceptions of national economic conditions. American Journal of Political Science 44, 635-653.

Duffy B (2018) The Perils of Perception: Why We're Wrong about Nearly Everything. London: Atlantic Books.

Dunning D (2011) The Dunning-Kruger effect: on being ignorant of one's own ignorance. Advances in Experimental Social Psychology 44, 247-296.

Einstein KL and Glick DM (2015) Do I think BLS data are BS? The consequences of conspiracy theories. Political Behavior 37, 679-701.

Enders AM and Smallpage SM (2018) Polls, plots, and party politics: conspiracy theories in contemporary America. In Uscinski JE (ed.), Conspiracy Theories and the People Who Believe Them. New York, NY: Oxford University Press, pp. 298-318.

Erisen C, Guidi M, Martini S, Toprakkiran S, Isernia P and Littvay L (2021) Psychological correlates of populist attitudes. Political Psychology. https://doi.org/10.1111/pops.12768

European Commission (2018) Eurobarometer 88.2 (2017). TNS opinion, Brussels [producer]. GESIS Data Archive, Cologne. Available at https://doi.org/10.4232/1.13005.

European Commission (2020) Eurobarometer 86.2 (2016). TNS opinion, Brussels [producer]. GESIS Data Archive, Cologne. ZA6788 Data file Version 2.0.0. Available at https://doi.org/10.4232/1.13602.

Eurostat (2020) Population on 1 January by age group, sex and citizenship. Available at http://ec.europa.eu/eurostat/product? code $=$ migr_poplctz\&language $=$ en\&mode $=$ view (Accessed on 10 February 2020).

Evans G and Andersen R (2006) The political conditioning of economic perceptions. Journal of Politics 68, $194-207$.

Flynn DJ, Nyhan B and Reifler J (2017) The nature and origins of misperceptions: understanding false and unsupported beliefs about politics. Advances in Political Psychology 38, 127-150.

Gallagher C (2003) Miscounting race: explaining whites' misperceptions of racial group size. Sociological Perspectives 46, 381-396.

Gigerenzer G and Edwards A (2003) Simple tools for understanding risks: from innumeracy to insight. BMJ: British Medical Journal 327, 741-744.

Goertzel T (1994) Belief in conspiracy theories. Political Psychology 15, 731-742.

Grzesiak-Feldman M (2013) The effect of high-anxiety situations on conspiracy thinking. Current Psychology 32, 100-118.

Hardin R (2002) Trust and Trustworthiness. New York: Russell Sage Foundation.

Herda D (2010) How many immigrants? Foreign-born population innumeracy in Europe. Public Opinion Quarterly 74, 674695.

Herda D (2013) Too many immigrants? Examining alternative forms of immigrant population innumeracy. Sociological Perspectives 56, 213-240.

Holt J (2008) Official statistics, public policy and public trust. Journal of Royal Statistical Society 171, 1-20.

Imhoff $\mathbf{R}$ and Bruder $\mathbf{M}$ (2014) Speaking (un-)truth to power: conspiracy mentality as a generalised political attitude. European Journal of Personality 28, 25-43.

Isernia P and Olmastroni F (2014) Images of the immigrant: European public opinion and immigration. In Ceccorulli M and Labanca N (eds), The EU, Migration and the Politics of Administrative Detention: Insights from Positive Psychology. Abingdon, Oxon: Routledge, pp. 59-78.

Jolley D and Douglas KM (2014) The social consequences of conspiracism: exposure to conspiracy theories decreases intentions to engage in politics and reduce one's carbon footprint. British Journal of Psychology 105, 35-56.

Jolley D, Douglas KM and Sutton RM (2018) Blaming a few bad apples to save a threatened barrel: the system justifying function of conspiracy theories. Political Psychology 39, 465-478, 35-56.

Jolley D, Meleady R and Douglas KM (2020) Exposure to intergroup conspiracy theories promotes prejudice which spreads across groups. British Journal of Psychology 111, 17-35.

King G and Roberts ME (2015) How robust standard errors expose methodological problems they do not fix, and what to do about it. Political Analysis 23, 159-179.

Kuklinski JH, Quirk PJ, Shwieder DW and Rich RF (1998) 'Just the facts, ma'am': political facts and public opinion. The ANNALS of the American Academy of Political and Social Science 560, 143-154.

Kunda Z (1990) The case for motivated reasoning. Psychological Bulletin 108, 480-498.

Lee S and Matsuo A (2018) Decomposing political knowledge: what is confidence in knowledge and why it matters. Electoral Studies 51, 1-13.

Leman PJ and Cinnirella M (2007) A major event has a major cause: evidence for the role of heuristics in reasoning about conspiracy theories. Social Psychological Review 9, 18-28.

Leman PJ and Cinnirella M (2013) Beliefs in conspiracy theories and the need for cognitive closure. Frontiers in Psychology 4, 378.

Lewandowsky S, Oberauer K and Gignac GE (2013) NASA faked the moon landing - therefore, (climate) science is a hoax: an anatomy of the motivated rejection of science. Psychological Science 24, 622-633. 
Lodge M and Taber CS (2013) The Rationalizing Voter. New York, NY: Cambridge University Press.

MacKinnon JG and White H (1985) Some heteroskedasticity-consistent covariance matrix estimators with improved finite sample properties. Journal of Econometrics 29, 305-325.

Mancosu M, Vassallo S and Vezzoni C (2017) Believing in conspiracy theories: evidence from an exploratory analysis of Italian survey data. South European Society and Politics 22, 327-344.

Mancosu M, Ladini R and Vassallo S (2021) Political consequences of conspirational thinking: evidence from 2016 Italian constitutional referendum. Acta Politica 56, 69-88.

Martinez MD, Wald KD and Craig SC (2008) Homophobic innumeracy? Estimating the size of the gay and lesbian population. Public Opinion Quarterly 72, 753-767.

McClosky H and Chong D (1985) Similarities and differences between left-wing and right-wing radicals. British Journal of Political Science 15, 329-363.

Moscovici S (1987) The conspiracy mentality. In Graumann CF and Moscovici S (eds), Changing Conceptions of Conspiracy. pp. 151-169. New York, NY: Springer.

Mudde C (1999) The single-issue party thesis: extreme right parties and the immigration issue. West European Politics 22, 182-197.

Nadeau R, Niemi RG and Levine J (1993) Innumeracy about minority populations. Public Opinion Quarterly 57, $332-347$.

Oliver JE and Wood TJ (2014) Conspiracy theories and the paranoid styles(s) of mass opinion. American Journal of Political Science 58, 952-966.

Paulos JA (1988) Innumeracy: Mathematical Illiteracy and its Consequences. New York: Hill and Wang.

Peters E (2006) Beyond comprehension: the role of numeracy in judgements and decisions. Current Directions in Psychological Science 21, 31-35.

Pettigrew TF, Allport GW and Barnett EO (1958) Binocular resolution and perceptions of race in South Africa. British Journal of Psychology 49, 265-278.

Quaranta M and Martini S (2019) A sinking boat? The refugee crisis and attitudes towards the European Union in Italy, 1993-2018. Italian Political Science 14, 129-148.

Quaranta M, Mancosu M and Martini S (2020) A tale of bias: longitudinal evidence of the effect of electoral defeat on citizens' evaluations of the economy. International Journal of Public Opinion Research 32, 604-620.

Scotto TJ, Reifler J, Hudson D and van Heerde-Hudson J (2017) We spend how much? Misperceptions, innumeracy, and support for the foreign aid in the United States and Great Britain. Journal of Experimental Political Science 4, 119-128.

Semyonov M, Rajiman R, Tov AY and Schmit P (2004) Population size, perceived threat, and exclusion: a multiple-indicators analysis of attitudes toward foreigners in Germany. Social Science Research 33, 681-701.

Strabac Z (2011) It is the eyes and not the size that matter. European Societies 13, 559-582.

Sutton RM and Douglas KM (2014) Examining the monological nature of conspiracy. In van Proojien JW and van Lange PAM (eds), Power, Politics and Paranoia. Cambridge: Cambridge University Press, pp. 254-272.

Swami V, Chamorro-Premuzic T and Furnham A (2010) Unanswered questions: a preliminary investigation of personality and individual difference predictors of 9/11 conspiracist beliefs. Applied Cognitive Psychology 24, 749-761.

Swami V, Voracek M, Stieger S, Tran US and Furnham A (2014) Analytic thinking reduces belief in conspiracy theories. Cognition 133, 572-585.

Taylor SE (1982) The availability bias in social psychology. In Kahneman D, Slovic P and Tversky A (eds), Judgement Under Uncertainty: Heuristics and Biases. London: Cambridge University Press, pp. 190-200.

Thränhardt D (1995) The political uses of xenophobia in England, France and Germany. Party Politics 1, 323-345.

Tukey JW (1977) Exploratory Data Analysis. Reading, MA: Addison-Wesley, Reading.

Tversky A and Kahneman D (1973) Availability: a heuristic for judging frequency and probability. Cognitive Psychology $\mathbf{5}$ 207-232.

UNHCR - United Nations High Commissioner for Refugees (2020) UNHCR Statistics. Available at https://bit.ly/2vNNptP (Accessed 10 February 2020).

van Proojien JW (2017) Why education predictions decreased belief in conspiracy theories. Applied Cognitive Psychology 31, 50-58.

Walker S (2019) Viktor Orbán Trumpets Hungary's 'Procreation, Not Immigration' Policy. The Guardian, September 6. Available at https://bit.ly/3atzXu5 (Accessed 25 March 2020).

Yeo I-K and Johnson RA (2000) A new family of power transformations to improve normality or symmetry. Biometrika 87, 954-959.

YouGov (2018) YouGov Cambridge Results - Conspiracy Theories. Available at https://bit.ly/2vNKHo9 (Accessed 25 March 2020).

Cite this article: Martini S, Guidi M, Olmastroni F, Basile L, Borri R, Isernia P (2022). Paranoid styles and innumeracy: implications of a conspiracy mindset on Europeans' misperceptions about immigrants. Italian Political Science Review/ Rivista Italiana di Scienza Politica 52, 66-82. https://doi.org/10.1017/ipo.2021.26 